\title{
Developing a Thermally Stable Ester-Based Drilling Fluid for Offshore Drilling Operations by Using Aluminum Oxide Nanorods
}

\author{
Alaa Ahmed ${ }^{1}$ (D), Amin Sharifi Haddad ${ }^{1, *}$, Roozbeh Rafati ${ }^{1}$, Ahmed Bashir ${ }^{1}$, Ahmed M. AlSabagh ${ }^{2}$ \\ and Amany A. Aboulrous ${ }^{3}$ \\ 1 School of Engineering, University of Aberdeen, Aberdeen AB24 3UE, UK; \\ alaa.ahmed.17@aberdeen.ac.uk (A.A.); roozbeh.rafati@abdn.ac.uk (R.R.); ahmed.bashir@abdn.ac.uk (A.B.) \\ 2 Petroleum Application Department, Egyptian Petroleum Research Institute, Cairo, Egypt; \\ alsabaghh@gmail.com \\ 3 Production Department, Egyptian Petroleum Research Institute, Cairo, Egypt; amany.a.aboulrous@gmail.com \\ * Correspondence: amin.sharifi@abdn.ac.uk
}

check for

updates

Citation: Ahmed, A.; Sharifi Haddad, A.; Rafati, R.; Bashir, A.; AlSabagh, A.M.; Aboulrous, A.A. Developing a Thermally Stable Ester-Based Drilling Fluid for Offshore Drilling Operations by Using Aluminum Oxide Nanorods. Sustainability 2021, 13, 3399.

https://doi.org/10.3390/su13063399

Academic Editor: Changhyun Roh

Received: 15 February 2021

Accepted: 15 March 2021

Published: 19 March 2021

Publisher's Note: MDPI stays neutral with regard to jurisdictional claims in published maps and institutional affiliations.

Copyright: (c) 2021 by the authors. Licensee MDPI, Basel, Switzerland. This article is an open access article distributed under the terms and conditions of the Creative Commons Attribution (CC BY) license (https:/ / creativecommons.org/licenses/by/ $4.0 /)$.

\begin{abstract}
Esters were found to be promising alternatives to oil, as a constituent of drilling fluids, due to their biodegradability and bioaccumulation attributes. In this study, we used ethyl octanoate ester (EO) as a low molecular weight synthetic oil for formulating an ester-based drilling fluid (EBDF). Aluminum oxide nanorods (nanoparticles) were introduced as a Pickering emulsion stabilizer. Like the commercial emulsifiers, they showed that they stabilized the invert emulsion drilling fluid in our study. The rheological and filtration properties of the EBDF were tested at normal pressure and three temperatures: low temperature deepwater (LT) conditions of $2.6^{\circ} \mathrm{C}$, normal pressure and normal temperature (NPNT) conditions of $26.8^{\circ} \mathrm{C}$, and elevated temperature conditions of $70{ }^{\circ} \mathrm{C}$. To enhance the stability and filtration properties of the drilling fluid, aluminum oxide nanoparticles (NPs) were used. An optimum concentration of $1 \mathrm{wt} \%$ was found to provide superior rheological performance and higher stability than samples without NPs at NPNT, LT, and elevated temperature conditions. Steadier gel rheology was exhibited at elevated temperature conditions, and a slow rate of an increasing trend occurred at the lower temperatures, with increasing NP concentrations up to $1.5 \mathrm{wt} \%$. Filtration loss tests presented a reduction of fluid loss with increasing the NP concentration. The results demonstrate that a reduction of up to $45 \%$ was achieved with the addition of $1 \mathrm{wt} \% \mathrm{NP}$. These results show that nano-enhancement of ethyl octanoate drilling fluids would suffice to provide a wider range of operational temperatures for deepwater drilling operations by providing better thermal stability at elevated temperatures and maintaining stability at lower temperatures.
\end{abstract}

Keywords: ester-based drilling fluid; ethyl octanoate; low temperature; nanoparticles

\section{Introduction}

Over the past several years, the exploration of oil and gas has significantly expanded in offshore and deepwater fields. There are abundant resources of oil and gas in deepwater zones that have triggered the interest in superfluous exploration. In offshore drilling operations, the drilling fluid is a key factor in overcoming the challenges of low temperature and gas hydrate formation. The variations in temperature in offshore operations, especially deepwater, affect the rheological properties of the drilling fluids, such as the viscosity and yield point, massively. These changes can lead to the initiation of lost circulation, difficulties in controlling the pressure, drilling fluid stability, and high equivalent circulating density (ECD). Oil-based drilling fluids (OBDFs) are preferred in offshore and deepwater drilling operations instead of water-based drilling fluids (WBDFs), due to their performance that leads to better lubrication and stability of rheological properties in environments with varying temperature conditions. 
In many regions around the world, such as the North Sea and the Gulf of Mexico, environmental regulations have been made to ban the use of diesel in oil-based drilling fluids since 1984. This is due to issues related to the toxicity of diesel affecting marine life [1]. Although WBDFs have a lower cost and are also biodegradable and non-toxic, they are not suitable to use in drilling complicated wells, such as in shale formations or high pressure and high temperature (HPHT) conditions. Ester-based oils were developed to comply with the marine ecosystem requirements of cuttings discharge that diesel failed to meet. Therefore, the dominance of EBDFs over commercial synthetic-based drilling fluids (SBDFs) is due to its minimal toxicity, as well as its biodegradability and bioaccumulation when drilling fluid design is considered. However, EBDFs have shown some limitations in challenging environments, such as deepwater drilling and marine sensitive conditions.

In this study, the main objective was the development of a nano-enhanced esterbased drilling fluid that has a wider range of operational temperatures, as an alternative circulating fluid for drilling operations; this drilling fluid would be compatible with cold offshore environments and elevated formation temperature conditions. Since the ability of the drilling fluid to perform its main functions (e.g., hole cleaning, cooling the bit, etc.) depends on the rheological and filtration properties, the application of nanoparticles in this EBDF was investigated. The results show that nano-enhancement is a potential way to improve the rheological and filter loss properties of the drilling fluid and reduce its degradation and hydrolysis at elevated temperatures.

\subsection{Ester-Based Drilling Fluids}

Over the past several years, studies have been conducted to understand the relation between the structure of ester and its effects on the properties of EBDFs. Esters' physicochemical properties (e.g., pour point, flash point, kinematic viscosity, hydrolytic and thermal stability) are highly dependent on the structures of the fatty acid derived from the alcohol during the chemical reaction and the functional group of the ester [2]. For ester-based drilling fluids, it is desired to have a fluid with a low pour point and viscosity. In addition, it is also essential to seek high hydrolytic and thermal stability during the selection of the ester [3]. The kinematic viscosity of the ester is crucial to consider since it expresses the fluid's tolerance to water and solids as additives during the drilling process [4]. A low kinematic viscosity would improve the pumpability; furthermore, the cost of expensive ester could be reduced by increasing the volume fraction of brine when formulating the drilling fluid $[5,6]$.

Therefore, to reduce the viscosity of the ester, the molecular flexibility should be increased in addition to a reduction in the molecular weight [1,7]. Drilling fluids formulated with base oils such as palm oil, coconut oil, and soybean oil that have long chains with high molecular weights, exhibit high plastic viscosities. This can trigger the fracturing of the formation in subsurface media if the equivalent circulating density is higher than the fracturing pressure. On the other hand, palm oil methyl ester and canola oil methyl ester, which are derivatives of triglycerides, consist of shorter chains with lower molecular weights; therefore, they exhibit low kinematic viscosity. Nevertheless, their high pour points still remain an issue in offshore and deepwater operations $[2,8]$. Therefore, there is an extremely narrow window for using drilling fluids due to the very low seawater temperature [4].

It has been recognized that esters that are derived from plant oils provide the best environmental performance out of the SBDFs. The emission of organic vapors from them is minimal relative to linear alpha olefins $\mathrm{LAO}$ and isomerized olefins (IO), and they undergo full biodegradability in both aerobic and anaerobic conditions [9-11]. When addressing biodegradation, bioaccumulation, lubricity, and eco-toxicity, EBDFs are also superior to other SBDFs; therefore, they are considered the best environmentally friendly options for drilling fluids. Yet, investigations are being continued to overcome issues in offshore drilling operations and complex boreholes to resolve challenges associated with offshore cold environments and HPHT conditions. Particularly in sensitive marine areas, EBDFs 
need to be enhanced for better performance in low temperature conditions while abiding environmental regulations [12,13].

In offshore applications, where the temperature is low, the rheology of the drilling fluid is affected by the kinematic viscosity and the pour point of the fluid [1]. At low temperatures, more rheological flexibility is permitted by the base oils with lower pour points. Therefore, esters that have a low symmetrical molecular structure, such as esters from saturated fatty acids, are favorable, as they have lower pour points $[6,14]$. On the other hand, due to the esters' hygroscopic nature, the hydrolysis reaction is generally undergone at temperatures higher than $140^{\circ} \mathrm{F}\left(60^{\circ} \mathrm{C}\right)$; below that, the reaction would happen slowly. To overcome and reduce the effects of hydrolysis in EBDFs, suitable metal-based additives could be used for faster heat dissipation to the subsurface environment, which would help to avoid the increase in temperature in drilling fluids. Some metals that are compatible with esters and can be used to minimize the rate of hydrolysis are aluminum and its alloys, copper, nickel, titanium, silver, chromium, and tin [6].

Sauki et al. [15] studied the use of $C_{12}-C_{14}$ palm oil-derived esters. In their research, the oil/water ratio content in the drilling fluid was maneuvered to select the preeminent EBDF. The drilling fluid with the oil/water ratio of 80:20 was selected as the optimum formulation for the EBDF, since a higher yield point was achieved compared to the drilling fluid developed with an oil/water ratio of 90:10. The rheological properties of the EBDF were compared with both Sarapar-based drilling fluids (a commercial drilling fluid) and a water-based drilling fluid (WBDF). Moreover, the EBDF filtration loss was similar to both Sarapar-based drilling fluids and less than the WBDF. However, its application in offshore and deepwater drilling operations is limited by the high pour point of the palm oil-derived ester used as the base fluid.

In a recent study by Said et al. [16], a palm methyl ester drilling fluid (PMDF) was compared with a commercial OBDF formulated with a low-toxicity mineral oil. The PMDF viscosity was found to be extremely high relative to the other low-toxicity mineral oils; this issue of the PMDF was resolved by using less clay, and an adequate ester/water ratio. The rheological properties of the drilling fluid remained stable up to $250^{\circ} \mathrm{F}\left(121^{\circ} \mathrm{C}\right)$ under 10,000 psi pressure. In addition, the drilling fluid, after hot rolling for $16 \mathrm{~h}$ at $280^{\circ} \mathrm{F}\left(141^{\circ} \mathrm{C}\right)$, did not deteriorate. However, it degraded at temperatures above $350^{\circ} \mathrm{F}\left(177^{\circ} \mathrm{C}\right)$. On the other hand, the PMDFs with high densities exhibited a loss of stability in their rheology profiles in low temperature conditions.

Orji et al. [17] investigated the formulation of $C_{10}$ esters, where the rheological properties of ethyl octanoate (EO) and octyl acetate (OA) were compared to a commercial synthetic-based drilling fluid at different temperatures ranging from $80^{\circ} \mathrm{F}\left(27^{\circ} \mathrm{C}\right)$ to $200^{\circ} \mathrm{F}$ $\left(93{ }^{\circ} \mathrm{C}\right)$. The results showed that the EO-based fluid had a $\mathrm{pH}$ of 6.73 , which is lower than the $\mathrm{pH}$ of 7.2 of a commercial fluid; an even lower value (4.62) was reported for the OA-based drilling fluid. While the pour point was below $-4{ }^{\circ} \mathrm{C}$ for all three drilling fluids, the flash point of the reference fluid $\left(219{ }^{\circ} \mathrm{C}\right)$ was much higher than the values for the two esters $\left(169.60{ }^{\circ} \mathrm{C}\right.$ and $171.72{ }^{\circ} \mathrm{C}$ for EO- and OA-based drilling fluids, respectively). The ester-based drilling fluids displayed low plastic viscosity (PV) and gel strength values at all the temperatures investigated. The lower flash points and shorter carbon chain lengths of EO and OA, compared to the reference fluid, contributed to the lower rheology profiles of the ester-based drilling fluids. The study suggested that increasing the number of appropriate additives used in formulating the drilling fluid, like organophilic clay, can improve the rheology profile of the drilling fluids that are formulated with the esters.

\subsection{Nano-Enhanced Drilling Fluids}

Studies have shown that the addition of nanoparticles is more effective than polymerbased additives as fluid loss control agents. Furthermore, the addition of nanoparticles (NPs) does not affect the density of the drilling fluid [18]. The high surface area-to-volume ratio of NPs and their small size $(<100 \mathrm{~nm})$ justify their use as a type of additive for improving the rheology and filtration properties of drilling fluids. These properties of 
NPs increase the interaction forces between polar molecules of water and drilling fluid additives and enhance the hole cleaning process $[19,20]$. In addition, they can improve other properties of the drilling fluids, such as thermal conductivity, heat transfer, wellbore stability, and shale inhibition [21-23].

Rafati et al. [22] reported that the role of nanofluids in enhancing viscosity is due to the increase in interaction forces between particles. It was also stated that metal NPs have high thermal conductivities in comparison to typical components of drilling fluids. Therefore, metal NPs can be effective heat conductors and, in turn, enhance the stability of the drilling fluids due to Brownian motion, which triggers better heat dissipation. The improved heat transfer property leads to less degradation of the drilling fluid at elevated temperatures, thus maintaining its rheological properties. However, Yu-Hua et al. [24] indicated that the thermal conductivity of nanofluids depends on the temperature, and it cannot be described by Brownian motion only. That is because changes in viscosity and agglomeration of particles could also occur with the variations in temperature. An increase in the temperature was found to reduce the surface energy and agglomeration of nanoparticles while lowering the viscosity that would enhance the Brownian motion.

Smith et al. [23] investigated the application of aluminum oxide nanoparticles to enhance the rheological and filtration properties of a WBDF in NPNT and HPHT conditions. They found that the thermal stability of the drilling fluid was increased by the addition of aluminum oxide NPs, compared to silica NPs, at concentrations ranging from $0.1 \mathrm{wt} \%$ to $1 \mathrm{wt} \%$. Lower fluid losses in HPHT conditions were observed with increasing the concentration of aluminum oxide NPs compared to silica NPs. In the meantime, a lower increase of shear stress was reported for the case of aluminum oxide NPs compared to silica NPs.

Nanoparticles (NPs) have been consequently used as Pickering emulsion stabilizers [25-27], which are solid particles that can stabilize emulsion either solely or in conjunction with emulsifiers [28]. Pickering particles cause a steric barrier between the aqueous droplets, thus preventing their coalescence [29]. This is due to their strong ability to adsorb irreversibly at the oil/water interface that covers each dispersed droplet [30-32].

Wang et al. [33] reported the influence of concentrations of metal oxide nanoparticles on the zeta potential and illustrated the influence of the surface charge of NPs on their aggregation. This aggregation property was linked to the zeta potential, which is a measure of colloidal particles' electrostatic interactions on its diffuse layer's inner boundary. Their experimental results showed that the zeta potential is affected by the temperature, the type of ion in suspension and its strength, as well as the pH. In another study by Beg et al. [34], the zeta potential and particle size were analyzed to show the attractive interaction between $\mathrm{TiO}_{2} \mathrm{NPs}$ and xanthan gum in WBDFs. The interaction between $\mathrm{TiO}_{2}$ and xanthan gum ensued a wider distribution range and higher average particle size. This resulted in improved rheological properties and filtration characteristics, and alleviated the thermal degradation of hot rolling experiments that were performed at $110{ }^{\circ} \mathrm{C}[34,35]$. In another study by Heister et al. [36], the zeta potential of multi-walled carbon nanotubes (MWCNTs) was measured with varying $\mathrm{pH}$. These measurements were used to determine the MWCNTs dispersion and their colloidal stability. The results showed that certain aspects, such as the appropriate $\mathrm{pH}$ and a low concentration of salt, improved the dispersion.

Ismail et al. [37] investigated the impact of multi-walled carbon nanotubes (MWCNTs) on the gel strength and emulsion stability of EBDFs. They reported that at higher concentrations of MWCNTs, a slight increase in the emulsion stability of the fluid was observed, and the gel strength was increased at elevated temperatures. This is due to the electrostatic forces between the MWCNTs and other components of the drilling fluid, which in turn, causes drilling fluid texture to be rigid and demonstrate an enhanced gel structure [37]. Other rheological properties, such as plastic viscosity, yield point, and filtration loss, were not tested for EBDFs.

Using nanoparticles to improve the performance of WBDFs has been proven through laboratory and field tests. However, limited studies have been conducted so far on the 
application of nanomaterials to enhance the properties of EBDFs. Razali et al. [1] suggested that the addition of nanoparticles to EBDFs would attain similar enhancement of the rheological and filtration loss properties as reported for the WBDFs. In their study, they highlighted that the dispersion of nanomaterials is a crucial criterion that would obtain the potential benefits in nano-enhanced EBDFs. However, they reported that the effect of nanoparticles on EBDFs' rheological properties has yet to be examined.

Synthetic-based drilling fluids, such as ester-based drilling fluids with environmentally friendly properties, are strong candidates for offshore and deepwater drilling operations. Nevertheless, previous reports were focused on using palm oil methyl ester (POME) as the base fluid. Although it is commercially used due to its similar performance to OBDFs, its use is limited in deepwater conditions due to its high pour point. Therefore, developing a drilling fluid that is compatible with deepwater or cold offshore drilling operations and has a lower environmental footprint is still a challenge.

\section{Methodology}

In our study, ethyl octanoate ester, as a base fluid, was used in the drilling fluids samples. Studies on the palm oil methyl ester-based drilling fluids showed promising rheological and filtration properties that were near to those of commercial drilling fluids, in comparison with ethyl octanoate-based drilling fluids. However, the palm oil methyl ester was not chosen due to its high pour point of $59^{\circ} \mathrm{F}\left(15^{\circ} \mathrm{C}\right)$, which restricts its application in low temperature deepwater conditions [17]. Ethyl octanoate, with a lower pour point $-40{ }^{\circ} \mathrm{F}\left(-40{ }^{\circ} \mathrm{C}\right)$, could be used as the base fluid to formulate an EBDF. This is because of the chemical formula of ethyl octanoate $\left(\mathrm{C}_{10} \mathrm{H}_{20} \mathrm{O}_{2}\right)$, which has a shorter carbon chain than palm oil methyl ester $\left(\mathrm{C}_{17} \mathrm{H}_{34} \mathrm{O}_{2}\right)$; therefore, ethyl octanoate, with a lower molecular weight, has a lower pour point and kinematic viscosity. However, ethyl octanoate has unfavorable thermal stability, that is, it undergoes hydrolysis at elevated temperatures, thus causing the drilling fluid to lose its rheological properties.

As suggested by Razali et al. [1], the introduction of nanoparticles to EBDFs may improve the thermal stability and rheological properties of EBDFs. Since the ethyl octanoate EBDFs showed low yet acceptable rheological properties, nanoparticles were added in different concentrations to determine their effects on enhancing the drilling fluids' properties. The selection of nanoparticles originated from a recent study by Smith et al. [23], who compared the use of aluminum oxide and silica nanoparticles to enhance the properties of WBDFs in NPNT and HPHT conditions. In their study, they concluded that aluminum oxide nanoparticles excelled in enhancing the thermal stability and lowering degradation rates when nanoparticles were used, even in small concentrations, to formulate WBDFs. Thus, aluminum oxide NPs were used to analyze the effects of these additives on stability, and the rheological and filtration properties of the EBDFs.

\subsection{Materials}

An invert (water-in-oil) emulsion drilling fluid was prepared. An ester/water ratio of 80:20, with ester as the continuous phase and brine (water and calcium chloride) as the emulsified phase, was used in this study. Based on previous studies by Sauki et al. [15], this ester/water ratio generates rheological properties comparable to a commercial drilling fluid called "Sarapar-based drilling fluid". Since it is a non-aqueous drilling fluid, the choice and performance of the emulsifier used to stabilize the coexistence of ester and water was a vital factor that directly affected the performance of the drilling fluid. Commercial primary and secondary emulsifiers (SUREMUL EH and SUREWET) were used to ensure there were stable water-in-oil emulsions in the EBDF structure.

Even though the surface area of aluminum oxide nanoparticles $\left(210,417 \mathrm{ft}^{2} / \mathrm{lb}_{\mathrm{m}}\right)$ is lower than the surface area of silica NPs $\left(920,576-1.18 \times 10^{6} \mathrm{ft}^{2} / \mathrm{lb}_{\mathrm{m}}\right)$, a high thermal conductivity (17 Btu/h.ft. ${ }^{\circ}$ F) of aluminum oxide NPs, compared to silica NPs $\left(0.81 \mathrm{Btu} / \mathrm{h} . \mathrm{ft} .{ }^{\circ} \mathrm{F}\right)$, makes them suitable for enhancing the thermal stability of drilling fluids [23]. Therefore, in this study, we used aluminum oxide NPs to improve the thermal stability of the EBDF. The 
aluminum oxides used were nanorods with lengths less than $50 \mathrm{~nm}$. The characteristics of the aluminum oxide NPs are presented in Table 1.

Table 1. The aluminum oxide nanorods characteristics (as provided by the Sigma Aldrich Company).

\begin{tabular}{cccccccc}
\hline Material & Color & $\begin{array}{c}\text { Molecular } \\
\text { Weight }\end{array}$ & Form & Description & $\begin{array}{c}\text { Size (Transmission } \\
\text { Electron Microscopes) }\end{array}$ & $\begin{array}{c}\text { Surface Area } \\
\text { (Bet) }\end{array}$ & $\begin{array}{c}\text { Melting } \\
\text { Point }\end{array}$ \\
\hline $\begin{array}{c}\text { Aluminum } \\
\text { Oxide }\end{array}$ & White & 101.96 & Rod & $\begin{array}{c}\text { Gamma } \\
\text { phase }\end{array}$ & $<3.28 \times 10^{-9} \mathrm{ft}(50 \mathrm{~nm})$ & $\begin{array}{c}>210,417 \\
\mathrm{ft}^{2} / \mathrm{lb}_{\mathrm{m}}()\end{array}$ & $2040{ }^{\circ} \mathrm{C}$ \\
\hline
\end{tabular}

In our study, we used $1.5 \mathrm{ppb}$ of ECOTROL (filtration control agent) and $1 \mathrm{ppb}$ of VG Supreme (gelling agent); these are consistent with the study conducted by Said et al. [16], in which an EBDF with $1 \mathrm{ppb}$ of ECOTROL and $2.5 \mathrm{ppb}$ of VG supreme was formulated.

\subsection{Apparatus}

A Hamilton Beach Mixer was used for mixing the base fluids and additives to prepare the EBDF samples, and their densities were measured by an OFITE Mud Balance. It should be noted that even at a high shear rate mixing with the Hamilton Mixer, re-agglomeration of NPs could occur due to the strong Van der Waals attractive forces. Therefore, a more efficient mixing can be achieved using ultrasonic baths and a magnetic stirrer, to mix the NPs with the brine solution at a high $\mathrm{pH}$ value (by adding lime), before the addition of other components [38]. To determine the rheology of the prepared samples, an OFITE Model 800 viscometer was used. Then, an OFITE filter press with a filter paper with $7.87 \times 10^{-5}-1.97 \times 10^{-4}$ in $2(2-5 \mu \mathrm{m})$ particle size retention was used to measure the filtration loss properties.

\subsection{Experimental Procedure}

The recommended mixing method was used to prepare the samples (one laboratory barrel is equal to $350 \mathrm{~mL}$ of drilling fluid) [39]. A standard time of 5 min of mixing was followed, after the addition of every component of the drilling fluid in the mixing order, recorded in Table 2, to achieve a drilling fluid density of $11 \mathrm{ppg}\left(1.32 \mathrm{~g} / \mathrm{cm}^{3}\right)$ and a $\mathrm{pH}$ value of 11 . The aluminum oxide nanoparticles were added to the aqueous phase by high shear mixing. Drilling fluid samples were placed inside ice buckets until reaching a temperature of $2.6^{\circ} \mathrm{C}$ to represent cold offshore conditions. An incubator was used to heat up the samples at a temperature of $70{ }^{\circ} \mathrm{C}$ for $16 \mathrm{~h}$ (aging period) to investigate the rheological and filtration properties comparable to field scenarios [23].

Table 2. Composition and order of mixing of the formulated ester-based drilling fluid (EBDF) samples.

\begin{tabular}{|c|c|c|c|c|}
\hline Material & Mixing Order & Concentration & Purpose & Source \\
\hline Ethyl octanoate ester & & $223.2 \mathrm{~mL}$ & Base fluid & Sigma Aldrich \\
\hline VG HT & 1 & $1 \mathrm{ppb}$ & High temperature Viscosifier & MI SWACO \\
\hline VG Supreme & & $1 \mathrm{ppb}$ & Gelling agent & MI SWACO \\
\hline Lime & 2 & $10 \mathrm{ppb}$ & Alkalinity agent & \\
\hline Primary emulsifier & & $8 \mathrm{ppb}$ & Emulsifier & MI SWACO \\
\hline Secondary emulsifier & 3 & $2 \mathrm{ppb}$ & Wetting agent & MI SWACO \\
\hline Water & & $55.8 \mathrm{~mL}$ & Emulsified fluid & \\
\hline Calcium chloride & 4 & $17.5 \mathrm{ppb}$ & Brine & \\
\hline $\begin{array}{l}\text { Aluminum oxide NPs } \\
\qquad(<50 \mathrm{~nm})\end{array}$ & & $0.1,0.2,0.5,1,1.5$ wt. $\%$ & $\begin{array}{l}\text { Thermal stabilizer } \\
\text { Filtration control }\end{array}$ & Sigma Aldrich \\
\hline Ecotrol & 5 & $1.5 \mathrm{ppb}$ & Filtration control & MI SWACO \\
\hline Barite & 6 & $180.4 \mathrm{ppb}$ & Weighting agent & \\
\hline Sodium carbonate & 7 & $4 \mathrm{ppb}$ & $\mathrm{pH}$ control & \\
\hline
\end{tabular}




\subsection{Mathematical Theory}

Drilling fluids demonstrate mainly non-Newtonian behaviors, in which viscosity varies with shear rates. There are different models to represent the behavior of drilling fluids. However, the Herschel-Bulkley model is the most accurate model to represent the rheology of drilling fluids, based on past studies [22,40].

This model is defined by the following equation:

$$
\tau=\tau_{0}+K \gamma^{n}
$$

where $\tau$ is the shear stress, $\tau_{0}$ is the yield point, $K$ is the consistency index, $\gamma$ is the shear rate, and $n$ is the flow behavior index. Using the experimental data obtained for the shear rate and shear stress, we were able to minimize the residual sum of squares (RSS) between the model, Equation (1), and experimental shear stresses. Thus, through the RSS method, the values of yield point, consistency index, and flow behavior index were estimated.

To measure the shear rate and shear stress, we used the conversion that a $1^{\circ}$ dial reading was equivalent to $1.067 \mathrm{lb}_{\mathrm{f}} / 100 \mathrm{ft}^{2}$ of shear stress, and $1 \mathrm{RPM}$ was equivalent to a $1.703 \mathrm{~s}^{-1}$ shear rate [41].

Furthermore, for comparison purposes, we used the Bingham Plastic model, which is a common and easy-to-implement model, to represent the rheology of drilling fluids (although it is less accurate). The rheological properties based on the Bingham Plastic model (plastic viscosity $\mathrm{PV}$, and yield point $\mathrm{YP}_{\mathrm{BP}}$ ), were calculated using the rheometer, as follows:

$$
\begin{gathered}
\mathrm{PV}(\mathrm{cP})=\theta_{600}-\theta_{300} \\
\mathrm{YP}_{\mathrm{BP}}\left(\mathrm{lb} / 100 \mathrm{ft}^{2}\right)=\theta_{300}-\mathrm{PV}
\end{gathered}
$$

where $\theta_{600}$ and $\theta_{300}$ are dial readings at 600 and 300 speeds (RPM), respectively.

\subsection{Coding}

There was a total of 18 samples investigated in this study, with the coding as shown in Table 3. The letter $\mathrm{T}$ in the coding denotes "temperature" and is followed by the value of the temperature $\left({ }^{\circ} \mathrm{C}\right)$ at which the sample was tested. $\mathrm{N}$ denotes the concentration of the aluminum oxide NPs and is followed by the numeric value ( $w \mathrm{t} \%)$ of the concentration. For example, “T70N0.5" represents the EBDF sample at $70{ }^{\circ} \mathrm{C}$ with $0.5 \mathrm{wt} \%$ aluminum oxide NPs added.

Table 3. The coding for the samples with different nanoparticle (NP) concentrations that are used in this study.

\begin{tabular}{cccc}
\hline Wt. \% Aluminum Oxide NPs & $\mathbf{2 . 6}{ }^{\circ} \mathbf{C}$ & $\mathbf{2 6 . 8}{ }^{\circ} \mathbf{C}$ & $\mathbf{7 0}{ }^{\circ} \mathbf{C}$ \\
\hline 0.0 & $\mathrm{~T} 2.6 \mathrm{~N} 0$ & $\mathrm{~T} 26.8 \mathrm{~N} 0$ & $\mathrm{~T} 0 \mathrm{~N} 0$ \\
0.1 & $\mathrm{~T} 2.6 \mathrm{~N} 0.1$ & $\mathrm{~T} 26.8 \mathrm{~N} 0.1$ & $\mathrm{~T} 70 \mathrm{~N} 0.1$ \\
0.2 & $\mathrm{~T} 2.6 \mathrm{~N} 0.2$ & $\mathrm{~T} 26.8 \mathrm{~N} 0.2$ & $\mathrm{~T} 70 \mathrm{~N} 0.2$ \\
0.5 & $\mathrm{~T} 2.6 \mathrm{~N} 0.5$ & $\mathrm{~T} 26.8 \mathrm{~N} 0.5$ & $\mathrm{~T} 70 \mathrm{~N} 0.5$ \\
1.0 & $\mathrm{~T} 2.6 \mathrm{~N} 1$ & $\mathrm{~T} 26.8 \mathrm{~N} 1$ & $\mathrm{~T} 0 \mathrm{~N} 1$ \\
1.5 & $\mathrm{~T} 2.6 \mathrm{~N} 1.5$ & $\mathrm{~T} 26.8 \mathrm{~N} 1.5$ & $\mathrm{~T} 70 \mathrm{~N} 1.5$ \\
\hline
\end{tabular}

\section{Results and Discussion}

The emulsion stability and the rheological and filtration properties of the formulated drilling fluid samples were evaluated at low, normal, and high temperatures. The density of the drilling fluid samples remained at $11 \pm 0.1 \mathrm{ppg}$.

\subsection{Visual Inspection for the Invert Emulsion (EBDF) Stability}

We found that the addition of at least $1 \mathrm{wt} \%$ NPs can improve the stability of the formulated drilling fluid significantly, as shown in Figure 1 (the drilling fluid samples were left in static conditions for $16 \mathrm{~h}$ in order to analyze their stabilities). Minimal separation of 
the liquid occurred in a sample with nanoparticles, compared to the base EBDF (without nanoparticles). This improvement was due to the dispersion of particles and hence, the electrostatic interaction between the colloidal particles [19,33].

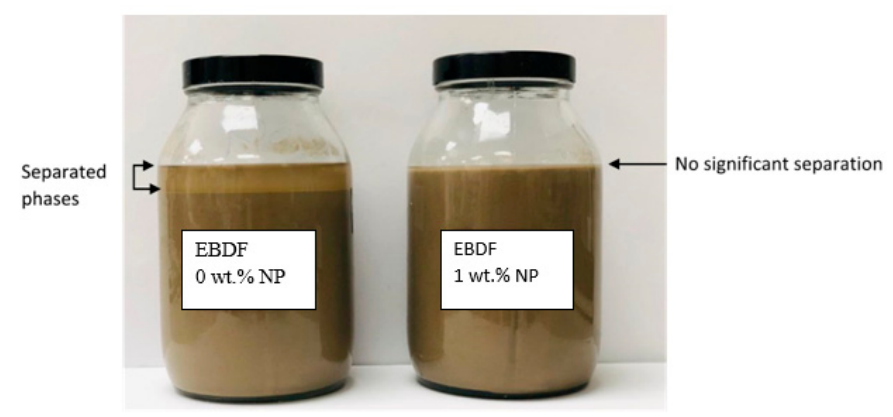

Figure 1. Stability of the base EBDF (left) and nano-enhanced EBDF with the $1 \mathrm{wt} \%$ NPs sample (right) after $16 \mathrm{~h}$ of static aging in ambient conditions.

The nanoparticles formed a protective skin around the dispersed droplet and consequently prevented re-coalescence [42]. Figure 2 shows a schematic of the Pickering emulsion mechanism. The stability of a Pickering emulsion depends on the nanoparticle's concentration. Thus, the adsorption rate of particles at the interface increases with the increase in the concentration of nanoparticles. In addition, smaller droplets will be produced with the increase in nanoparticle concentration, which will reduce the rate of re-coalescence.

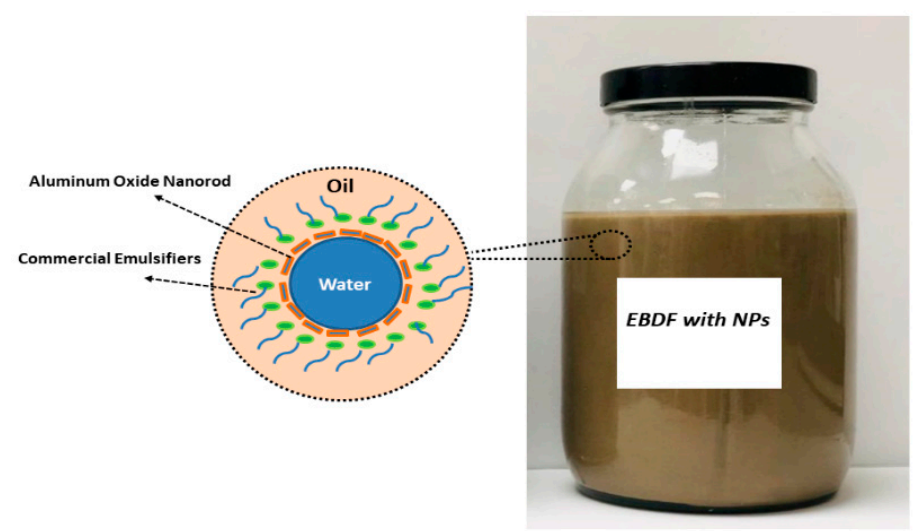

Figure 2. The mechanism of stabilizing the water-in-oil emulsion in the EBDF using aluminum oxide nanorods.

\subsection{Rheological Properties in NPNT Conditions}

Before the addition of nanoparticles, the formulated EBDF was tested at low $\left(2.6^{\circ} \mathrm{C}\right)$, ambient $\left(26.8^{\circ} \mathrm{C}\right)$, and elevated $\left(70^{\circ} \mathrm{C}\right)$ temperatures. Figure 3 displays the shear stress versus the shear rate of the base EBDF at different temperatures. It shows that, at higher temperatures, the shear stress was reduced. 


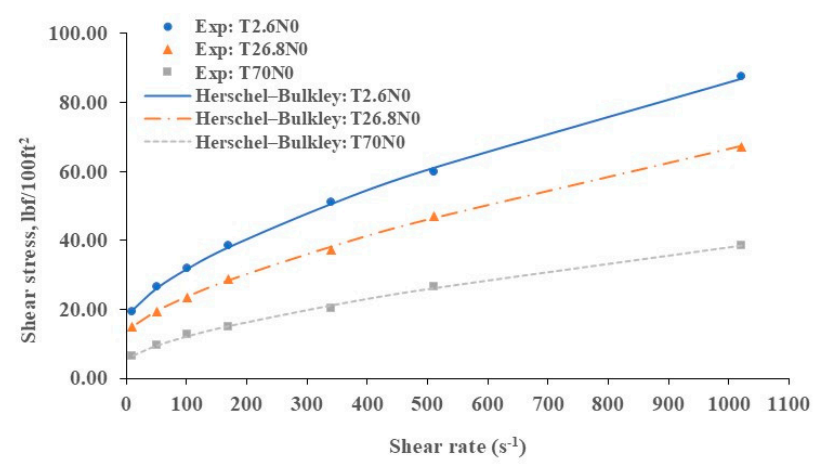

Figure 3. Shear stress versus shear rate of the EBDF in different temperature conditions. Symbols: experimental data; lines: Herschel-Bulkley model.

In the next experiments, we added nanoparticles to the drilling fluid and evaluated its performance. Figure 4 shows the shear stress versus the shear rate for the EBDFs, with different NP concentrations in normal pressure and normal temperature conditions. It demonstrates that, at the reported range of concentrations, the shear stress increased with increasing NP concentrations. Table 4 shows the values of the yield point, the consistency index, and the flow behavior index in the Herschel-Bulkley model. Based on the HerschelBulkley model, the $\tau_{0}$ dropped from $12.59 \mathrm{lb}_{\mathrm{f}} / 100 \mathrm{ft}^{2}$ to $8.29 \mathrm{lb}_{\mathrm{f}} / 100 \mathrm{ft}^{2}$ with the addition of $0.1 \mathrm{wt} \% \mathrm{NP}$; it then increased with increasing NP concentrations up to $17.54 \mathrm{lb}_{\mathrm{f}} / 100 \mathrm{ft}^{2}$. The values of the consistency index, $\mathrm{K}$, increased with increasing NP concentrations (0.44-0.78), while the flow behavior index, $\mathrm{n}$, decreased from 0.7 to 0.63 with the addition of nanoparticles. This means that a higher concentration of nanoparticles was beneficial for a higher yield point and a lower $\mathrm{n}$ value; however, the $\mathrm{K}$ value increased with a higher concentration of nanoparticles.

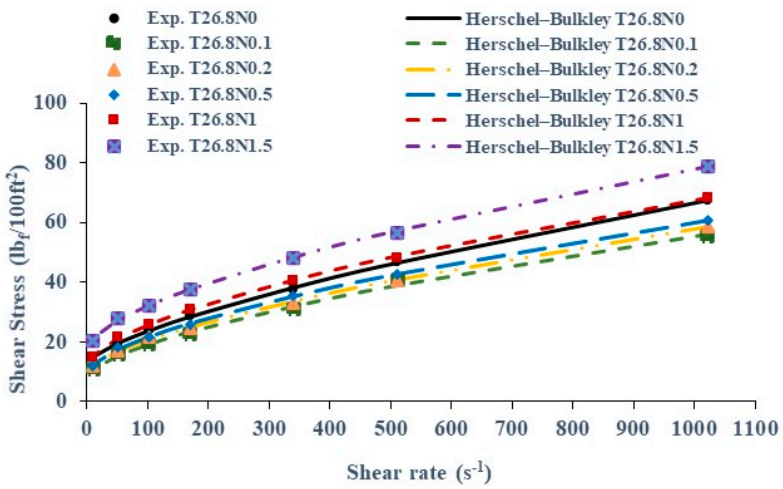

Figure 4. Shear stress versus shear rate at normal pressure and normal temperature (NPNT) conditions $\left(26.8^{\circ} \mathrm{C}\right)$. Symbols: experimental data; lines: Herschel-Bulkley model.

Table 4. The yield point, consistency index, and flow behavior index for the Herschel-Bulkley model at $26.8^{\circ} \mathrm{C}$.

\begin{tabular}{cccc}
\hline EBDF Code & $\boldsymbol{\tau}_{\mathbf{0}}\left(\mathbf{l b}_{\mathbf{f}} / \mathbf{1 0 0 f t}^{\mathbf{2}}\right)$ & $\mathbf{K}$ & $\mathbf{n}$ \\
\hline T26.8N0 & 12.59 & 0.44 & 0.70 \\
\hline T26.8N0.1 & 8.29 & 0.56 & 0.64 \\
\hline T26.8N0.2 & 9.90 & 0.51 & 0.66 \\
\hline T26.8N0.5 & 9.27 & 0.68 & 0.63 \\
\hline T26.8N1 & 11.97 & 0.80 & 0.61 \\
\hline T26.8N1.5 & 17.54 & 0.78 & 0.63 \\
\hline
\end{tabular}


A comparison of the rheological properties of the base EBDF with previous studies is shown in Figure 5. The rheological properties of the EBDF were analyzed against the rheological properties of the palm methyl ester-based drilling fluid (PMDF), Sarapar-based drilling fluid (a commercial OBDF), and a WBDF, reported by Sauki et al. [15]. All these samples have similar mud weights; however, the Sarapar-based drilling fluid, PMDF, and WBDF displayed higher and progressive gel strength properties compared to the EBDF (T26.8N0). This is because of the low viscosity of the ethyl octanoate that was used in sample T26.8N0 (it has a shorter carbon chain in its structure), compared to other oils [4]. This can highlight the advantages of improved pumpability and reduced frictions that can be achieved by the EBDFs formulated.

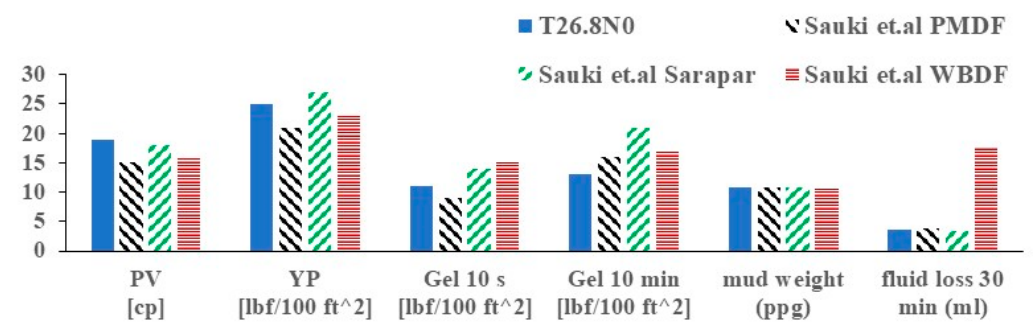

Figure 5. Rheological properties of the EBDF sample compared with Sauki et al.'s PMDF (palm methyl ester-based drilling fluid), Sarapar-based drilling fluid (commercial OBDF), and WBDF in NPNT conditions [15].

The outcomes of our analyses of the nano-enhanced EBDF are shown in Figure 6. The rheological properties explicate that the addition of aluminum oxide NPs slightly increased the PV, however, the changes are not significant.

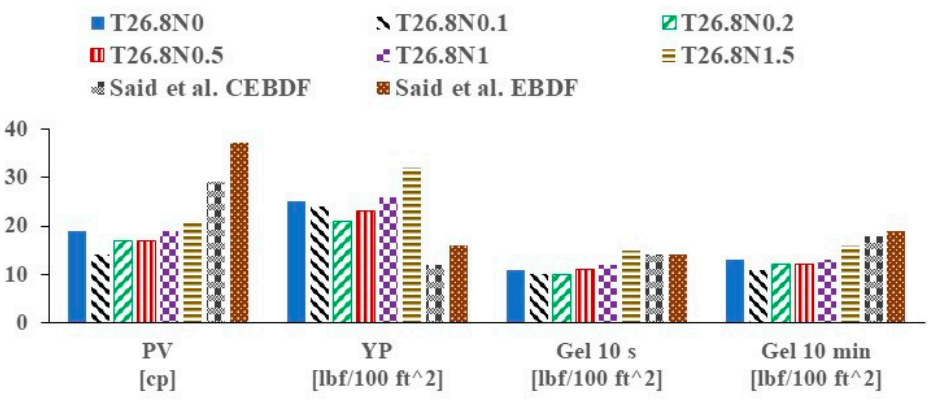

Figure 6. Rheological properties of nano-enhanced EBDF in NPNT conditions $\left(26.8^{\circ} \mathrm{C}\right)$.

A decrease in the PV was observed by the addition of $0.1 \mathrm{wt} \% \mathrm{NP}$. According to Katende et al. [30], this reduction is attributed to the ability of NPs to interrupt the formation of gel between the particles in the drilling fluids with low mud weight. With the higher concentrations of NPs, that is, 1 , and $1.5 \mathrm{wt} \%$, the $\mathrm{PV}, \mathrm{YP}_{\mathrm{BP}}$, and gel strengths either remained unchanged or slightly increased in comparison to sample T26.8N0. The increase in the rheological properties is due to an increase in the concentration of solid particles, which results in higher zeta potential. An increase of the zeta potential causes an improvement in the electrostatic repulsion, which in turn, demonstrates enhanced dispersion stability, and higher frictions between the fluids' layers in an ester-based suspension system. An increase in drilling fluids' properties that exceeds the acceptable ranges should be avoided, as this means pumpability can be an issue. Also, static conditions of a drilling fluid for a long time (as shown by "Gel, $10 \mathrm{~min}$ ") may cause some bindings between the nanoparticles and other solids components, that are not easy to break. Therefore, based on these data, a maximum of $1 \mathrm{wt} \% \mathrm{NP}$ can be used to have a stable EBDF, with the properties remaining almost unchanged, compared to the base sample in NPNT conditions.

When our EBDFs were compared to the reported results by Said et al. for their commercial ester-based drilling fluid (CEBDF), all samples had a lower PV and a higher 
YP. The gel strengths at $10 \mathrm{~s}$ and $10 \mathrm{~min}$ for the CEBDF samples [16] were higher compared to the samples with and without nanoparticles in this study. Therefore, the ethyl octanoate ester can give a better performance compared to the CEBDF and EBDF reported by Said et al. (lower PV and gel strengths, and a higher YP).

\subsection{Rheological Properties in Simulated Deepwater Conditions $\left(2.6^{\circ} \mathrm{C}\right)$ and an Elevated Temperature $\left(70^{\circ} \mathrm{C}\right)$}

The rheological properties of the nano-enhanced drilling fluids were evaluated at low and high temperature conditions, that is, at $2.6^{\circ} \mathrm{C}$ and $70{ }^{\circ} \mathrm{C}$, respectively. The samples at $2.6^{\circ} \mathrm{C}$ and $70{ }^{\circ} \mathrm{C}$ displayed large increases in the shear stress with $1.5 \mathrm{wt} \%$ nanoparticle concentration, as shown in Figure 7, while at lower concentrations, the changes were either insignificant or within the acceptable range. The corresponding values of the Herschel-Bulkley model are presented in Table 5. It shows that at both $2.6^{\circ} \mathrm{C}$ and $70{ }^{\circ} \mathrm{C}$, $\tau_{0}$ demonstrated an increasing trend, in general, with increasing NP concentrations. The consistency index, K, first decreased with increasing the NP concentrations, then increased with the further addition of NPs, at both low and high temperatures, and the flow behavior index, $\mathrm{n}$, decreased with the addition of nanoparticles at a low temperature; however, it shows an increasing trend with the addition of nanoparticles at a high temperature. Therefore, based on the above analyses at three temperatures, the rheological behavior of the ester-based drilling fluid could be optimized at an optimum concentration of nanoparticles.
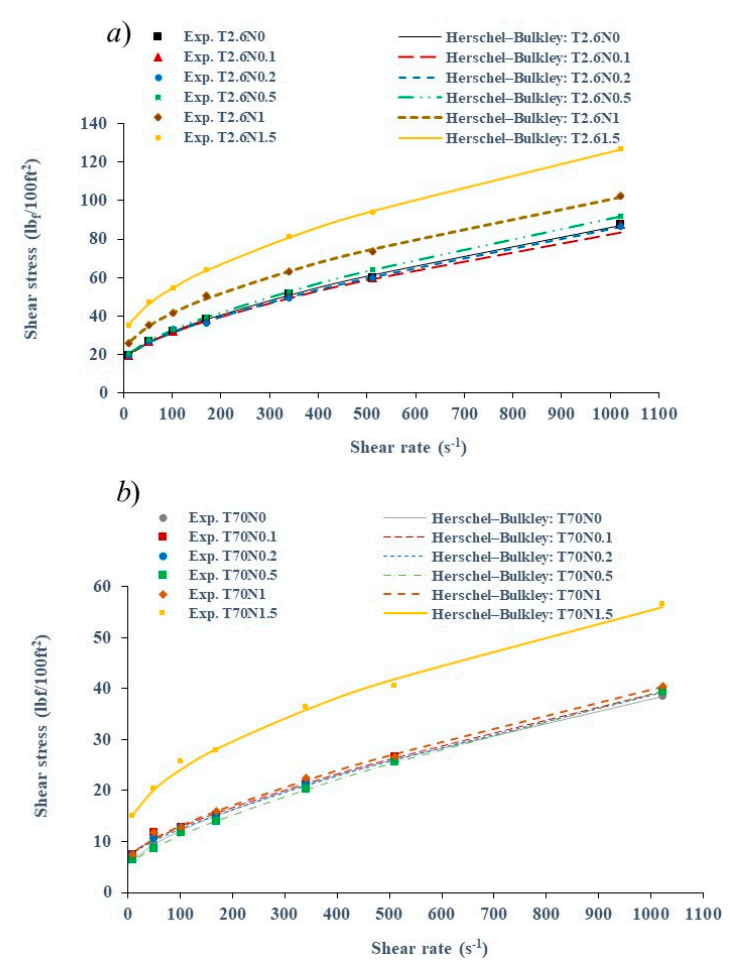

Figure 7. Shear stress versus shear rate of nano-enhanced EBDF at (a) $2.6^{\circ} \mathrm{C}$, and (b) $70{ }^{\circ} \mathrm{C}$. Symbols: experimental data; lines: Herschel-Bulkley model.

It should be noted that the samples demonstrated thermal stability, as they did not break at $70{ }^{\circ} \mathrm{C}$, and showed a steadiness in the shear stress.

Other rheological properties of the nano-enhanced drilling fluids were investigated, as shown in Figure 8. It displays a comparison of the rheological properties of the nanoenhanced ester-based drilling fluid (EBDF) from this study with a commercial low-impact drilling fluid (LIDF) reported by Kakadjian et al. [43] at an LT of $4.4{ }^{\circ} \mathrm{C}$. The PV remained almost unchanged up to a $1 \mathrm{wt} \% \mathrm{NP}$ concentration, while the $\mathrm{YP}_{\mathrm{BP}}$ showed a significant increase at 1 and $1.5 \mathrm{wt} \% \mathrm{NP}$ concentration. Since a low PV and a high $\mathrm{YP}_{\mathrm{BP}}$ is desirable, the T2.6N1 sample, with a $1 \mathrm{wt} \%$ NP concentration, exhibited the optimum PV/YP $\mathrm{BP}_{\mathrm{BP}}$ value 
in low temperature conditions in comparison to the LIDF. The gel strengths at $10 \mathrm{~s}$ and $10 \mathrm{~min}$ did not experience a jump from $10 \mathrm{~s}$ to $10 \mathrm{~min}$, as compared to the LIDF reported by Kakadjian et al. [43].

Table 5. The yield point, consistency index, and flow behavior index for the Herschel-Bulkley model at $2.6{ }^{\circ} \mathrm{C}$ (left) and $70{ }^{\circ} \mathrm{C}$ (right).

\begin{tabular}{cccccccc}
\hline EBDF Code & $\boldsymbol{\tau}_{\mathbf{0}}\left(\mathbf{l} \mathbf{b}_{\mathbf{m}} / \mathbf{1 0 0 f t} \mathbf{~}^{\mathbf{2}}\right)$ & $\mathbf{K}$ & $\mathbf{n}$ & EBDF Code & $\boldsymbol{\tau}_{\mathbf{0}}\left(\mathbf{l} \mathbf{b}_{\mathbf{m}} / \mathbf{1 0 0 f t}^{\mathbf{2}}\right)$ & $\mathbf{K}$ & $\mathbf{n}$ \\
\hline T2.6N0 & 16.3 & 0.74 & 0.66 & T70N0 & 4.9 & 0.34 & 0.66 \\
\hline T2.6N0.1 & 16.3 & 0.73 & 0.65 & T70N0.1 & 7.0 & 0.20 & 0.73 \\
\hline T2.6N0.2 & 17.2 & 0.58 & 0.69 & T70N0.2 & 6.8 & 0.17 & 0.75 \\
\hline T2.6N0.5 & 17.3 & 0.69 & 0.68 & T70N0.5 & 5.2 & 0.19 & 0.75 \\
\hline T2.6N1 & 20.7 & 1.38 & 0.59 & T70N1 & 6.8 & 0.23 & 0.72 \\
\hline T2.6N1.5 & 28.6 & 1.86 & 0.57 & T70N1.5 & 12.1 & 0.92 & 0.56 \\
\hline
\end{tabular}

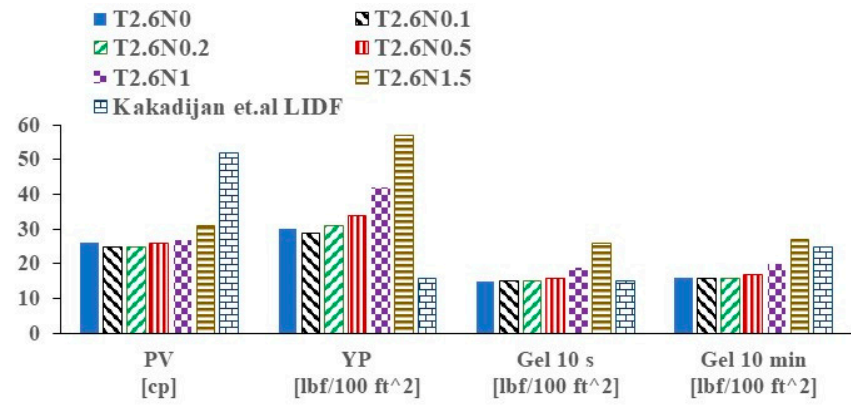

Figure 8. Rheological properties of nano-enhanced drilling fluids at $2.6^{\circ} \mathrm{C}$ compared to the lowimpact drilling fluid (LIDF) results from Kakadjian et al. [43].

The rheological properties for EBDF samples at $70^{\circ} \mathrm{C}$ are shown in Figure 9. The samples were compared with an ester-based drilling fluid formulated with ethyl octanoate (EOBDF), and a commercial SBDF (CSBDF) at the same temperature [17]. The PV and $\mathrm{YP}_{\mathrm{BP}}$ were evaluated to ensure that they were within the acceptable ranges. $\mathrm{PV}$ is desired to be low and range from 10-60 $\mathrm{cP}$ (preferably, 15-40 cP), while $\mathrm{YP}_{\mathrm{BP}}$ is desired to be high, within the range of 5-40 lb/100 ft ${ }^{2}$ (preferably, 10-25 lb/100 $\mathrm{ft}^{2}$ ), when tested at $50{ }^{\circ} \mathrm{C}$, above which, hydrolysis can occur [8]. The results from this study demonstrate an increase of PV with the addition of nanoparticles at $70^{\circ} \mathrm{C}$. Although there was a significant decrease in $\mathrm{YP}_{\mathrm{BP}}$ compared to low temperature cases, the values of $\mathrm{YP}_{\mathrm{BP}}$ for all samples remained within the accepted ranges [40]. A decrease in the $\mathrm{YP}_{\mathrm{BP}}$ with the addition of nanoparticles was observed in Figure 9, up to $0.5 \mathrm{wt} \% \mathrm{NP}$, followed by an increase in $\mathrm{YP}_{\mathrm{BP}}$ at $1 \mathrm{wt} \% \mathrm{NP}$, with the highest $\mathrm{YP}_{\mathrm{BP}}$ at $1.5 \mathrm{wt} \%$ NP. This behavior could be attributed to the surface charges of particles that cause attraction/repulsion forces. By adding nanoparticles that have a larger surface area, and hence there would be a more effective distribution of charges on their surfaces, the interaction forces between the suspended particles would be higher. This leads to the modification of rheological behavior, that is, a reduced yield point at lower concentrations (due to better dispersion), and then Brownian motion and higher friction between fluid layers at higher nanoparticle concentrations, increasing the viscosity [22]. In a controlled volume, the nanoparticles are dispersed and attracted to the suspended phases, which can avoid agglomeration, and thus, cause greater attraction forces that enhance the $\mathrm{YP}_{\mathrm{BP}}$. The gel strength properties demonstrated higher values for the samples with nanoparticle concentrations of $1 \mathrm{wt} \%$ and $1.5 \mathrm{wt} \%$, with the samples displaying a steady gel strength at $10 \mathrm{~min}$. The EOBDF and CSBDF still displayed lower rheological properties as compared to the samples from our study. 


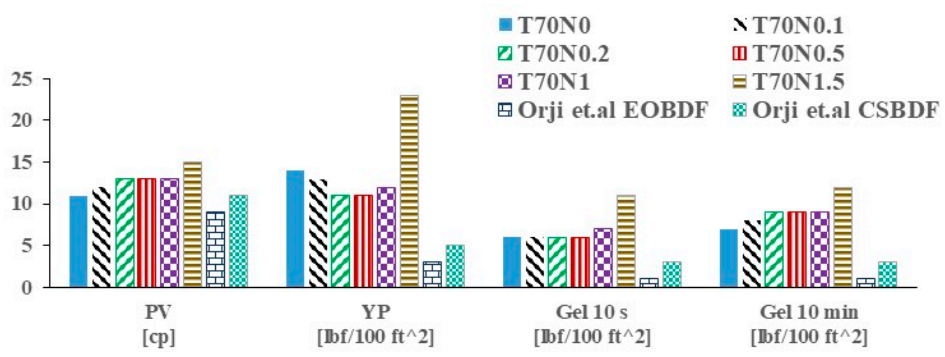

Figure 9. Rheological properties of the EBDF samples compared to Orji et al.'s EOBDF and CSBDF at $70{ }^{\circ} \mathrm{C}[17]$.

Figure 10 shows the variations in PV with the increasing nanoparticle concentrations, and a decrease of PV with increasing temperatures. A study by Vryzas et al. [38] confirmed that this behavior is attributed to the increase of emulsion stability caused by the addition of nanoparticles (aluminum nanocomposites and MWCNTs), which in turn, increases the $\mathrm{PV}$. On the other hand, an increase of $\mathrm{YP}_{\mathrm{BP}}$ occurs with increases in the concentration of NPs. At $2.6{ }^{\circ} \mathrm{C}, \mathrm{YP}_{\mathrm{BP}}$ increased after the addition of $0.2 \mathrm{wt} . \% \mathrm{NP}$, and at $26.8^{\circ} \mathrm{C}$ and $70{ }^{\circ} \mathrm{C}$ after the addition of $1 \mathrm{wt} . \%$ NP. The improvement in yield point is due to the large surface area-to-volume ratio of nanoparticles, which increased the attraction forces between the components of the drilling fluid suspended between the polar molecules of ester and water. At $1.5 \mathrm{wt} \%$, a high jump of $\mathrm{YP}_{\mathrm{BP}}$ was noticed at $\mathrm{LT}$; although a high $\mathrm{YP}_{\mathrm{BP}}$ is desired particularly at high temperatures, a fairly high $\mathrm{YP}_{\mathrm{BP}}$ would lead to flocculation and thus, a decrease in the rate of penetration (ROP) and loss of pump pressure [30].

a)

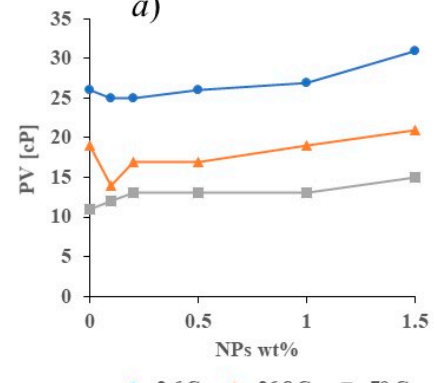

$-26 \mathrm{C} \rightarrow 26.8 \mathrm{C}-70 \mathrm{C}$ b)

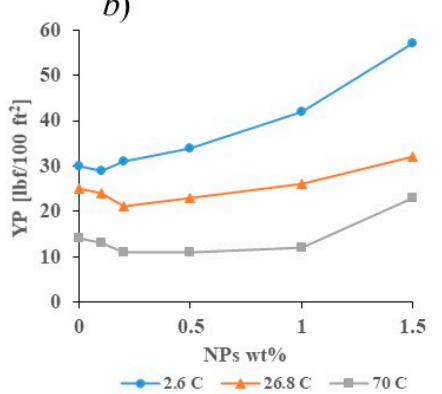

Figure 10. Summary of the effect of increasing wt.\% NP on (a) the plastic viscosity (PV) and (b) the yield point $\left(\mathrm{YP}_{\mathrm{BP})}\right.$, of $\mathrm{EBDF}$.

As shown in Figure 11, the gel strengths at $10 \mathrm{~s}$ and $10 \mathrm{~min}$ remain almost unchanged when increasing the nanoparticle concentration to $0.5 \mathrm{wt} \% \mathrm{NP}$, and they increased with increasing NP concentrations from $0.5-1.5 \mathrm{wt} \%$. This is due to the electrostatic forces between the nanoparticles and other polar components that cause them to be linked strongly with each other and form a stronger gel [44]. However, at higher temperatures, heat transfer becomes important and at higher nanoparticle concentrations, the rate of heat dissipation increases; this can help avoid faster water evaporation and minimize the potentials of ester hydrolysis. Therefore, the samples with nanoparticles remained stable at high temperatures, and the gel strengths of the samples with nanoparticles at high temperatures became steadier. Thus, the nanoparticle concentration of $1 \mathrm{wt} \%$ that produced a stable suspension system with reasonable $\mathrm{PV}$ and $\mathrm{YP}_{\mathrm{BP}}$ and did not show a significant increase in gel strength values (at three temperature conditions) can be considered to be an optimum concentration. 
a)

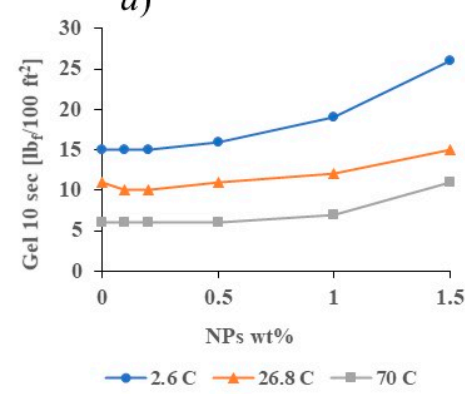

b)

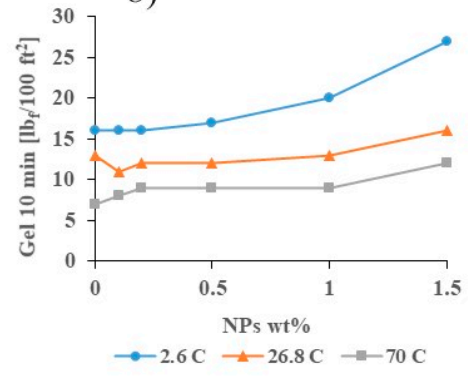

Figure 11. Summary of gel strength at (a) $10 \mathrm{~s}$ and (b) $10 \mathrm{~min}$, of nano-enhanced EBDF with increasing $w \mathrm{t} \% \mathrm{NP}$ at different temperatures.

\subsection{Filtration Loss at NPNT}

The fluid loss volume for an American Petroleum Institute (API) filter press test (at an ambient temperature and $690 \mathrm{kPa}$ ) is presented in Figure 12. It shows a decreasing trend for the filtrate volume with the addition of nanoparticles to the ester-based drilling fluid, as the fluid loss (at $30 \mathrm{~min}$ ) was reduced from $2.38 \mathrm{~mL}$ to $1.3 \mathrm{~mL}$. The lowest fluid loss volume was recorded when the concentration of NPs was increased to $1 \mathrm{wt} \%$. However, an increase to $1.5 \mathrm{~mL}$ occurred with the addition of $1.5 \mathrm{wt} \%$, confirming the preeminent concentration to be $1 \mathrm{wt} \% \mathrm{NP}$ for filtration loss. This supports the theory behind the addition of nanoparticles to reduce the loss by plugging the small pores, as they have been pushed by the pressure difference between the wellbore and the formation. The PMDF, Sarapar-based drilling fluid, and the WBDF that were studied by Sauki et al. [15], showed fluid loss volumes of $3.9 \mathrm{~mL}, 3.5 \mathrm{~mL}$, and $17.8 \mathrm{~mL}$, respectively, at $30 \mathrm{~min}$, which are higher filtrate volumes compared to the EBDF in this study. In addition, the filter cake thickness was reduced with increasing concentrations of nanoparticles, from $2.41 \mathrm{~mm}$ to $1.05 \mathrm{~mm}$ (50\% reduction), as shown in Figure 12c. This reduction is also consistent with studies conducted by Saboori et al. [45], in which they reported a reduction of $20-50 \%$ of mud cake thickness with increasing concentrations of nanoparticles.
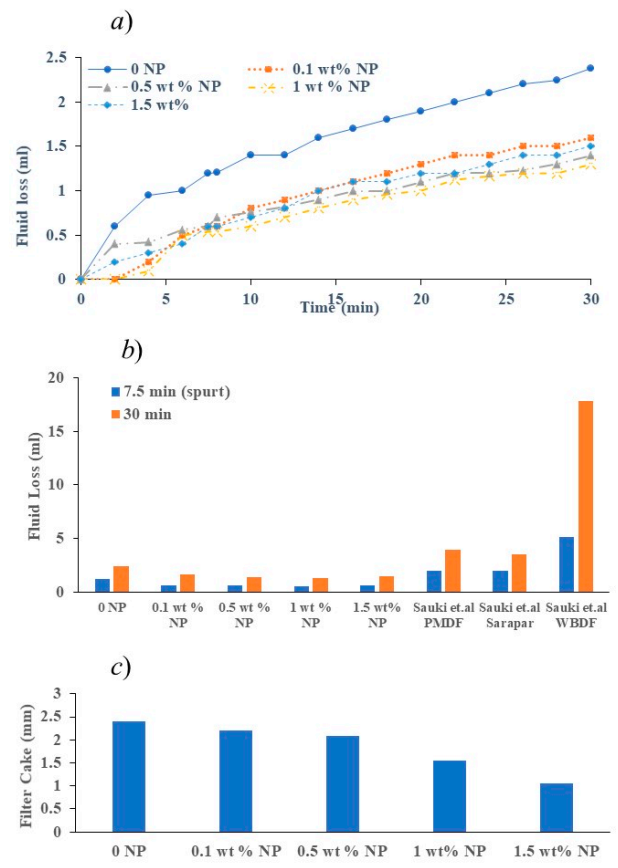

Figure 12. Filter press test comparison with previous studies: (a,b) fluid loss properties of nanoenhanced EBDF and (c) filter cake thickness of nano-enhanced EBDF, at ambient temperature. 


\section{Conclusions and Recommendations}

An investigation on the rheological and filtration properties of the EBDF in NPNT conditions, low temperature (simulated deepwater) conditions at $2.6{ }^{\circ} \mathrm{C}$, and at an elevated temperature of $70^{\circ} \mathrm{C}$, was conducted. Aluminum oxide nanoparticles were found to be promising additives to enhance the rheological and filtration properties of the EBDF at an optimum concentration. They can lower the risk of a hydrolysis reaction of the ester through higher rates of heat transfer and, in turn, stabilize the drilling fluid. The formulated EBDF exhibited better YP and gel strength properties compared to the previous studies on EBDFs and PMDFs. The EBDF in this study has the benefit of pumpability at a lower temperature range, compared to PMDFs, in addition to its lower PV and more stable rheology.

The rheological properties of the nano-enhanced EBDF were tested in LT, NPNT, and elevated temperature conditions with various concentrations of nanoparticles $(0.1,0.2,0.5$, 1 , and $1.5 \mathrm{wt} \%$ ). The results show an improvement of rheological properties and stability at high temperatures, delaying the hydrolysis of the ester. The best performance was recorded for the drilling fluid with a nanoparticle concentration of $1 \mathrm{wt} \%$. This suggests that EBDF with $1 \mathrm{wt} \%$ NP can be used for low temperature offshore drilling in shallow depths, and where the formation temperature is as high as $70^{\circ} \mathrm{C}$.

In this study we used one type of nanoparticle and ester; therefore, the following are some recommendations for further research:

- Comparison of the performance of aluminum oxide nanoparticles with other types of nanoparticles that are compatible with esters, such as MWCNT nanoparticles.

- Conducting experiments using different esters (preferably, branched-chain ones) to compare and determine the preeminent ester as a base fluid, depending on the drilling operations.

Author Contributions: Conceptualization, A.S.H. and R.R.; methodology, A.S.H., R.R., A.A. and A.B.; validation, A.A. and A.B.; formal analysis, A.S.H., A.A., A.A.A. and A.M.A.; investigation, A.S.H., A.A., A.B., and R.R.; resources, A.S.H., and R.R.; data curation, A.A. and A.B.; writingoriginal draft preparation, A.A.; writing-review and editing, A.S.H., A.A., R.R., A.A.A. and A.M.A.; visualization, A.A. and A.S.H.; supervision, A.S.H. and R.R.; project administration, A.S.H. and R.R.; funding acquisition, A.S.H., R.R., A.A.A. and A.M.A. All authors have read and agreed to the published version of the manuscript.

Funding: This work was supported by an Institutional Links grant, ID 352343681, under the NewtonMosharafa Fund partnership. The grant is funded by the UK Department for Business, Energy and Industrial Strategy, and Science, Technology \& Innovation Funding Authority (STDF) and delivered by the British Council. For further information, please visit www.newtonfund.ac.uk. Science, Technology \& Innovation Funding Authority (STDF) support was under the grant No. (30894).

Institutional Review Board Statement: Not applicable.

Informed Consent Statement: Not applicable.

Data Availability Statement: The data presented in this study are available on request from the corresponding author. The data are not publicly available due to commercialization purposes.

Acknowledgments: The authors would like to acknowledge the School of Engineering at the University of Aberdeen for providing the required facilities to complete this research. In addition, the authors would like to thank the support from MI-SWACO in providing commercial emulsifiers and consumables used in this project.

Conflicts of Interest: The authors declare no conflict of interest. 


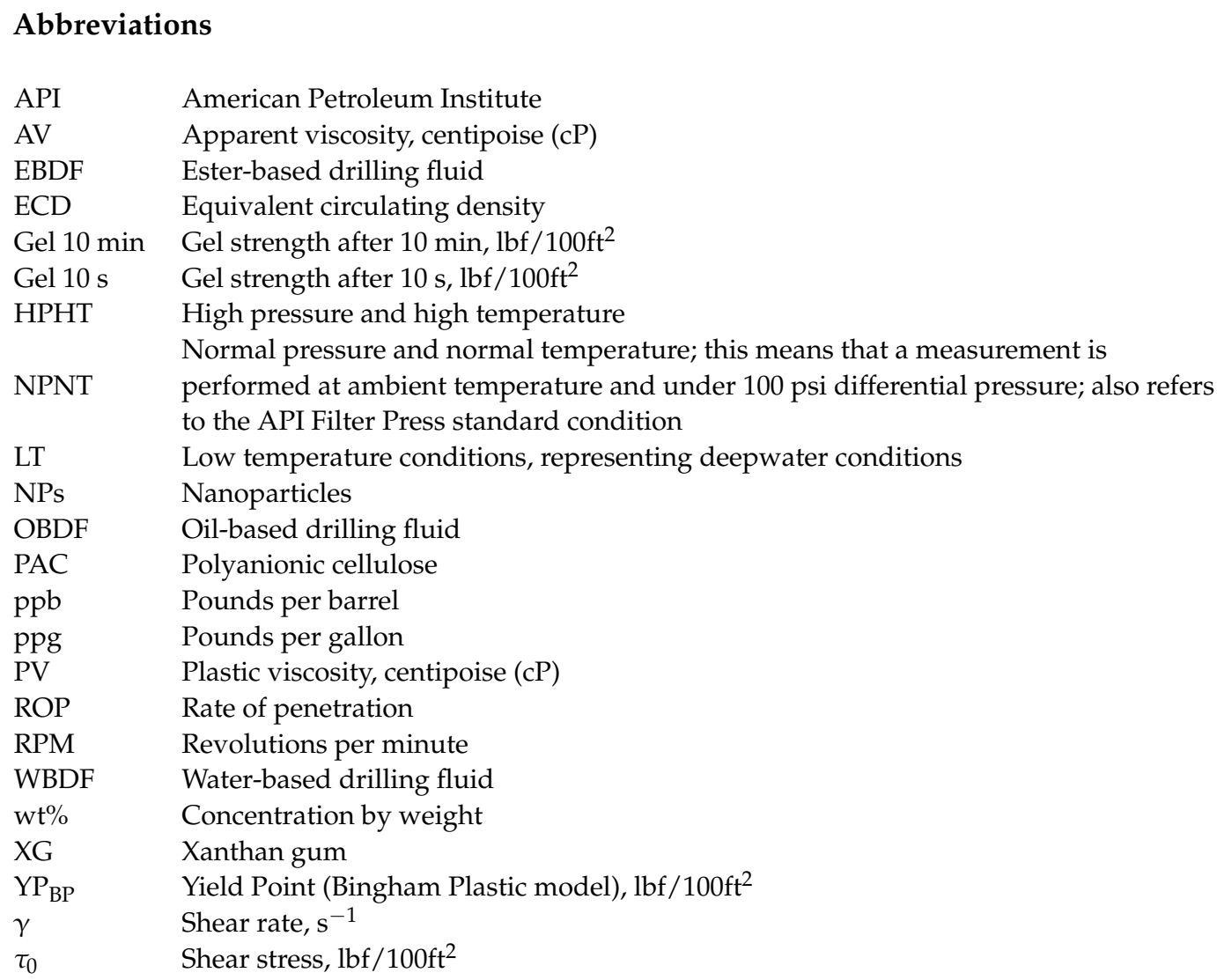

\section{References}

1. Razali, S.; Yunus, R.; Rashid, S.A.; Lim, H.; Jan, B.M. Review of biodegradable synthetic-based drilling fluid: Progression, performance and future prospect. Renew. Sustain. Energy Rev. 2018, 90, 171-186. [CrossRef]

2. Knothe, G.H. Chapter 2: Biodiesel and its properties. In Industrial Oil Crops, 1st ed.; McKeon, T.A., Hayes, D.G., Hildebrand, D.F., Weselake, R.J., Eds.; AOCS Press: Urbana, IL, USA, 2016; pp. 15-42.

3. Lyons, W.C.; Plisga, G.J.; Lorenz, M.D. Standard Handbook of Petroleum and Natural Gas Engineering; Chapter 4-Drilling and Well Completions; Gulf Professional Publishing: Woburn, MA, USA, 2015; pp. 4-1-4-584.

4. Burrows, K.; Evans, J.; Hall, J.; Kirsner, J. New low viscosity ester is suitable for drilling fluids in deepwater applications. In Proceedings of the SPE/EPA/DOE Exploration and Production Environmental Conference, San Antonio, TX, USA, 26-28 February 2001.

5. $\quad$ Eckhout, D.; Dolan, S.; Gogan, R.; Ledgister, H.; Mowat, C.; Tipton, P.; Dye, W. Development process and field applications of a new ester-based mud system for ERD wells on Australia's northwest shelf. In Proceedings of the ADC/SPE Asia Pacific Drilling Technology, Kuala Lumpur, Malaysia, 11-13 September 2000.

6. Rudnick, L. Chapter 3: Esters-Synthetics, Mineral Oils, and Bio-Based Lubricants: Chemistry and Technology; CRC Press, Taylor \& Francis Group: Boca Raton, FL, USA, 2013; pp. 47-63.

7. Ismail, A.; Kamis, A.; Foo, K. Performance of the mineral blended ester oil-based drilling fluid systems. In Proceedings of the Canadian International Petroleum Conference, Calgary, AB, Canada, 12-14 June 2001.

8. Mueller, H.; Herold, C.P.; Von Tapavicza, S.; Grimes, D.J.; Braun, J.M.; Smith, S.P. Use of Selected Ester Oils in Drilling Fluids and Muds. U.S. Patent 5232910A, 1999.

9. Imevbore, V.O.; Nwankwo, J.N.; Ifeadi, C.N.; Ladan, M.D. Laboratory assessment of biodegradation of non soluble drilling mud base fluids under Nigerian environmental conditions. In Proceedings of the SPE International Conference on Health, Safety and Environment in Oil and Gas Exploration and Production, Stavanger, Norway, 26-28 June 2000.

10. Neff, J.; Mckelvie, S.; Ayers, R.C., Jr. Environmental Impacts of Synthetic Based Drilling Fluids; U.S. Department of the Interior Minerals Management Service Gulf of Mexico OCS Region: Washington, DC, USA, 2000; pp. 30-52.

11. Steber, J.; Herold, C.-P.; Limia, J. Comparative evaluation ofanaerobic biodegradability of hydrocarbons and fatty derivatives currently used as drilling fluids. Chemosphere 1995, 31, 3105-3118. [CrossRef]

12. Cordes, E.E.; Jones, D.O.B.; Schlacher, T.A.; Amon, D.J.; Bernardino, A.F.; Brooke, S.; Carney, R.; DeLeo, D.M.; Dunlop, K.M.; Escobar-Briones, E.G.; et al. Environmental Impacts of the Deep-Water Oil and Gas Industry: A Review to Guide Management Strategies. Front. Environ. Sci. 2016, 4. [CrossRef]

13. Tornero, V.; Hanke, G. Chemical contaminants entering the marine environment from sea-based sources: A review with a focus on European seas. Mar. Pollut. Bull. 2016, 112, 17-38. [CrossRef] [PubMed] 
14. Ellice, M.; Helmy, S.; Shumate, T. Base Oil for Well-Bore Fluids. WO1996022342, 25 July 1996.

15. Sauki, A.; Shah, M.S.Z.; Bakar, W.Z.W. Application of Ester based drilling fluid for shale gas drilling. In Proceedings of the IOP Conference Series: Materials Science and Engineering; IOP Publishing: Bristol, UK, 2015; Volume 83, p. 012012.

16. Said, M.M.; El-Sayed, A.A.H. The use of palm oil fatty acid methyl ester as a base fluid for a flat rheology high-performance drilling fluid. J. Petroleum Sci. Eng. 2018, 166, 969-983. [CrossRef]

17. Orji, I.; Ibezim-Ezeani, M.U.; Akaranta, O. Evaluation of C10 Esters as Synthetic Base Fluids for Drilling Mud Formulation. IOSR J. Appl. Chem. 2016, 9, 31-38. [CrossRef]

18. Ghasemi, N.; Mirzaee, M.; Aghayari, R.; Maddah, H. Investigating Created Properties of Nanoparticles Based Drilling Mud. Heat Mass Transf. 2017, 54, 1381-1393. [CrossRef]

19. Boyou, N.V.; Ismail, I.; Sulaiman, W.R.W.; Haddad, A.S.; Husein, N.; Hui, H.T.; Nadaraja, K. Experimental investigation of hole cleaning in directional drilling by using nano-enhanced water-based drilling fluids. J. Pet. Sci. Eng. 2019, 176, 220-231. [CrossRef]

20. Krishnan, S.; Abyat, Z.; Chok, C. Characterization of boron-based nanomaterial enhanced additive in water-based drilling fluids: A study on lubricity, drag, ROP and fluid loss improvement. In Proceedings of the SPE/IADC Middle East Drilling Technology Conference and Exhibition, Abu Dhabi, United Arab Emirates, 26 January 2016.

21. Cheraghian, G. Application of Nano-Particles of Clay to Improve Drilling Fluid. Int. J. Nanosci. Nanotechnol. 2017, 13, 177-186.

22. Rafati, R.; Smith, S.R.; Haddad, A.S.; Novara, R.; Hamidi, H. Effect of nanoparticles on the modifications of drilling fluids properties: A review of recent advances. J. Pet. Sci. Eng. 2018, 161, 61-76. [CrossRef]

23. Smith, S.R.; Rafati, R.; Haddad, A.S.; Cooper, A.; Hamidi, H. Application of aluminium oxide nanoparticles to enhance rheological and filtration properties of water based muds at HPHT conditions. Colloids Surfaces Physicochem. Eng. Asp. 2018, 537, 361-371. [CrossRef]

24. Yu-Hua, L.; Wei, Q.; Jian-Chao, F. Temperature Dependence of Thermal Conductivity of Nanofluids. Chin. Phys. Lett. 2008, 25, 3319-3322. [CrossRef]

25. Wu, J.; Ma, G.-H. Recent Studies of Pickering Emulsions: Particles Make the Difference. Small 2016, 12, 4633-4648. [CrossRef]

26. Destribats, M.; Gineste, S.; Laurichesse, E.; Tanner, H.; Leal-Calderon, F.; Héroguez, V.; Schmitt, V. Pickering Emulsions: What Are the Main Parameters Determining the Emulsion Type and Interfacial Properties? Langmuir 2014, 30, 9313-9326. [CrossRef] [PubMed]

27. Binks, B.P.; Kirkland, M. Interfacial structure of solid-stabilised emulsions studied by scanning electron microscopy. Phys. Chem. Chem. Phys. 2002, 4, 3727-3733. [CrossRef]

28. Pickering, S.U. CXCV.-The chemistry of bordeaux mixture. J. Chem. Soc. Trans. 1907, 91, 1988-2001. [CrossRef]

29. Khan, A.Y.; Talegaonkar, S.; Iqbal, Z.; Ahmed, F.J.; Khar, R.K. Multiple Emulsions: An Overview. Curr. Drug Deliv. 2006, 3 , 429-443. [CrossRef]

30. Katende, A.; Boyou, N.V.; Ismail, I.; Chung, D.Z.; Sagala, F.; Hussein, N.; Ismail, M.S. Improving the performance of oil based mud and water based mud in a high temperature hole using nanosilica nanoparticles. Colloids Surfaces Physicochem. Eng. Asp. 2019, 577, 645-673. [CrossRef]

31. Luo, D.; Wang, F.; Chen, J.; Zhang, F.; Yu, L.; Wang, D.; Willson, R.C.; Yang, Z.; Ren, Z. Poly(sodium 4-styrenesulfonate) Stabilized Janus Nanosheets in Brine with Retained Amphiphilicity. Langmuir 2018, 34, 3694-3700. [CrossRef]

32. Li, M.C.; Wu, Q.; Song, K.; French, A.D.; Mei, C.; Lei, T. pH-responsive water-based drilling fluids containing bentonite and chitin nanocrystals. ACS Sustain. Chem. Eng. 2018, 6, 3783-3795. [CrossRef]

33. Wang, N.; Hsu, C.; Zhu, L.; Tseng, S.; Hsu, J.-P. Influence of metal oxide nanoparticles concentration on their zeta potential. J. Colloid Interface Sci. 2013, 407, 22-28. [CrossRef] [PubMed]

34. Beg, M.; Kumar, P.; Choudhary, P.; Sharma, S. Effect of high temperature ageing on TiO2 nanoparticles enhanced drilling fluids: A rheological and filtration study. Upstream Oil Gas Technol. 2020, 5, 100019. [CrossRef]

35. Cheraghian, G.; Hemmati, M.; Bazgir, S. Application of $\mathrm{TiO}_{2}$ and fumed silica nanoparticles and improve the performance of drilling fluids. AIP Conf. Proc. 2014, 1590, 266-270. [CrossRef]

36. Heister, E.; Lamprecht, C.; Neves, V.; Tîlmaciu, C.; Datas, L.; Flahaut, E.; Soula, B.; Hinterdorfer, P.; Coley, H.M.; Silva, S.R.P.; et al. Higher Dispersion Efficacy of Functionalized Carbon Nanotubes in Chemical and Biological Environments. ACS Nano 2010, 4, 2615-2626. [CrossRef] [PubMed]

37. Ismail, A.R.; Rashid, N.M.; Jaafar, M.Z.; Sulaiman, W.R.W.; Buang, N.A. Effect of Nanomaterial on the Rheology of Drilling Fluids. J. Appl. Sci. 2014, 14, 1192-1197. [CrossRef]

38. Vryzas, Z.; Kelessidis, V.C. Nano-Based Drilling Fluids: A Review. Energies 2017, 10, 540. [CrossRef]

39. MI SWACO. Drilling Fluids Engineering Manual; MI SWACO: Houston, TX, USA, 2001.

40. Mitchell, R.F.; Miska, S.Z. Chapter 3: Drilling Fluids. Fundamentals of drilling engineering. Soc. Petroleum Eng. 2017, 12, 144.

41. Caenn, R.; Darley, H.C.H.; Gray, G.R. Chapter 5-The Rheology of Drilling Fluids. In Composition and Properties of Drilling and Completion Fluids, 6th ed.; Gulf Professional Publishing: Houston, TX, USA, 2011; pp. 179-269.

42. Ghosn, R.; Mihelic, F.; Hochepied, J.-F.; Dalmazzone, D. Silica Nanoparticles for the Stabilization of W/O Emulsions at HTHP Conditions for Unconventional Reserves Drilling Operations. Oil Gas Sci. Technol. Rev. IFP Energ. Nouv. 2017, 72, 21. [CrossRef]

43. Kakadjian, E.; Shi, A.; Porter, J.; Yadav, P.; Clapper, D.; Pessanha, W. Low impact drilling fluid for deepwater drilling frontier. In Proceedings of the Offshore Technology Conference, Rio de Janeiro, Brasil, 30 October 2019. 
44. Ismail, A.; Aftab, A.; Ibupoto, Z.; Zolkifile, N. The novel approach for the enhancement of rheological properties of water-based drilling fluids by using multi-walled carbon nanotube, nanosilica and glass beads. J. Pet. Sci. Eng. 2016, 139, 264-275. [CrossRef]

45. Saboori, R.; Sabbaghi, S.; Kalantariasl, A.; Mowla, D. Improvement in filtration properties of water-based drilling fluid by nanocarboxymethyl cellulose/polystyrene core-shell nanocomposite. J. Pet. Explor. Prod. Technol. 2018, 8, 445-454. [CrossRef] 